\title{
Influence of Gas Annealing on Sensitivity of AlN/4H-SiC-Based Temperature Sensors
}

\author{
Seung-Woo Jung ${ }^{1,2}$, Myeong-Cheol Shin ${ }^{1,2} \oplus$, Michael A. Schweitz ${ }^{1}$, Jong-Min $\mathrm{Oh}^{1}$ and Sang-Mo Koo ${ }^{1, *}$ \\ 1 Department Electronic Materials Engineering, Kwangwoon University, 20 Kwangwoon-ro, Nowon-gu, \\ Seoul 01897, Korea; swjung0819@kw.ac.kr (S.-W.J.); smc0753@naver.com (M.-C.S.); \\ michael.schweitz@schweitzlee.com (M.A.S.); jmOh@kw.ac.kr (J.-M.O.) \\ 2 Department of Electrical and Mechanical Engineering, Nagoya Institute of Technology, Gokisocho, \\ Showa Ward, Nagoya, Aichi 466-8555, Japan \\ * Correspondence: smkoo@kw.ac.kr; Tel.: +82-2-940-5763
}

Citation: Jung, S.-W.; Shin, M.-C.; Schweitz, M.A.; Oh, J.-M.; Koo, S.-M. Influence of Gas Annealing on Sensitivity of AlN/4H-SiC-Based Temperature Sensors. Materials 2021, 14, 683. https://doi.org/10.3390/ ma14030683

Academic Editor: Yasuto Hijikata

Received: 9 January 2021

Accepted: 30 January 2021

Published: 2 February 2021

Publisher's Note: MDPI stays neutral with regard to jurisdictional claims in published maps and institutional affiliations.

Copyright: (c) 2021 by the authors. Licensee MDPI, Basel, Switzerland. This article is an open access article distributed under the terms and conditions of the Creative Commons Attribution (CC BY) license (https:// creativecommons.org/licenses/by/ $4.0 /)$.

\begin{abstract}
In this study, the physical and electrical characteristics of an AlN/4H-SiC Schottky barrier diode-based temperature sensor annealed in various gas atmospheres were investigated. An aluminum nitride (AlN) thin film was deposited on a $4 \mathrm{H}-\mathrm{SiC}$ substrate via radio-frequency sputtering followed by annealing in $\mathrm{N}_{2}$ or $\mathrm{O}_{2}$ gas. The chemical composition of the film was determined by $\mathrm{X}$-ray photoelectron spectroscopy (XPS) before and after annealing, and its electrical properties were evaluated by plotting a current-voltage (I-V) curve. The voltage-temperature (V-T) characteristics of the sensor were extracted from the current-voltage-temperature (I-V-T) plots constructed in the temperature range between 475 and $300 \mathrm{~K}$ in steps of $25 \mathrm{~K}$. Sensitivities of 9.77, 9.37, and $2.16 \mathrm{mV} / \mathrm{K}$ were obtained for the as-grown, $\mathrm{N}_{2}$-annealed, and $\mathrm{O}_{2}$-annealed samples, respectively.
\end{abstract}

Keywords: AlN; 4H-SiC; temperature sensor; Schottky barrier diodes; XPS

\section{Introduction}

Silicon carbide $(\mathrm{SiC})$ is a promising next-generation semiconductor composed of silicon and carbon. It possesses a wide bandgap $(3.2 \mathrm{eV})$, good physical properties, low leakage current, high thermal conductivity, excellent electron mobility, and high critical electric field [1]. Thus, $\mathrm{SiC}$ can be used in high-temperature and high-power electronic devices as well as in inverters of electric vehicles and aerospace applications. In addition, SiC exhibits a high thermal and chemical stability and a small crystal lattice mismatch with aluminum nitride (AlN), which is another wide bandgap semiconductor of high interest. These properties make $\mathrm{SiC}$ a most suitable substrate material for epitaxially grown AlN films. AlN is a III-V compound semiconductor with a large bandgap of $6.2 \mathrm{eV}$, high melting point of $3200 \mathrm{~K}$, high thermal conductivity of $3.2 \mathrm{~W} / \mathrm{mK}$, and high thermal and chemical stability, similar to those of $\mathrm{SiC}[2,3]$. The wide bandgap of AlN makes it suitable for photoelectric applications, including deep ultraviolet detectors and various sensors. AlN thin films can be grown by different methods including molecular beam epitaxy, metal organic chemical vapor deposition, pulsed laser deposition, and radio-frequency (RF) sputtering [3]. Sputter deposition enables the growth of large area, highly uniform, inexpensive, and high-quality AlN thin films at relatively low temperatures in a wide deposition range [4,5]. Meanwhile, gas annealing is an important process performed during the fabrication of compound semiconductors, which can increase the AlN crystallinity [6] and reduce the number of defects. The manufactured SBDs show promise for use in combined sensors for measuring both temperature and UV-light. Further sensing capabilities are being explored in related work [7-12]. In this study, Schottky barrier diode (SBD)-based temperature sensor samples were fabricated by RF sputtering deposition of AlN onto an n-type $4 \mathrm{H}-\mathrm{SiC}$ substrate. A number of the samples were subsequently annealed in either a nitrogen or oxygen 
atmosphere after which sensor parameters were investigated to establish the effects of the applied annealing gas.

\section{Materials and Methods}

AlN thin films were deposited on n-type $4 \mathrm{H}$-SiC substrates containing n-type epitaxial $4 \mathrm{H}-\mathrm{SiC}$ layers by RF sputtering of an AlN target (99.9\%) in an argon atmosphere (99.999\%) at room temperature. The sputtering power was $160 \mathrm{~W}$, with a gas flow rate of $4.0 \mathrm{sccm}$, as maintained by a mass flow controller. The chamber pressure was held at 25 mTorr during the $5 \mathrm{~h}$ deposition process. AlN film thickness was measured using a stylus profiler (SP) and atomic force microscopy (AFM). According to [13], AFM thickness measurements are in good agreement with measurements performed by ellipsometry. The resulting $400 \mathrm{~nm}$ thick AlN film samples were annealed at $500{ }^{\circ} \mathrm{C}$ for $1 \mathrm{~h}$ in two different atmospheres $\left(\mathrm{N}_{2}\right.$ or $\left.\mathrm{O}_{2}\right)$ using an annealing furnace. Finally, top electrodes of nickel were deposited on the AlN films to a thickness of $60 \mathrm{~nm}$ by means of an e-beam evaporator. Then, the samples were subjected to rapid thermal annealing at $950{ }^{\circ} \mathrm{C}$ for $60 \mathrm{~s}$ in an $\mathrm{N}_{2}$ atmosphere to form ohmic contacts. Figure 1 shows the SBD structure of the manufactured devices. The devices fabricated without annealing or with annealing in either a $\mathrm{N}_{2}$ or $\mathrm{O}_{2}$ atmosphere are herein named "as-grown", " $\mathrm{N}_{2}$-annealed", and " $\mathrm{O}_{2}$-annealed", respectively. Note that the current level degradation for all the devices remains within less than $10 \%$ of the initial level after a six-hour long exposure to elevated temperature $(675 \mathrm{~K})$. The detailed results of the comparative stress test study will be discussed elsewhere. The compositions of their AlN films were determined by X-ray photoelectron spectroscopy (XPS) before deposition of the top electrodes. Finally, to evaluate the effects of the different annealing conditions on the temperature sensing properties of the completed devices, their I-V-T characteristics were measured using a Keithley 4200-SCS (Tektronix, Beaverton, OR 97077, USA) for temperatures ranging from 300 to $475 \mathrm{~K}$.

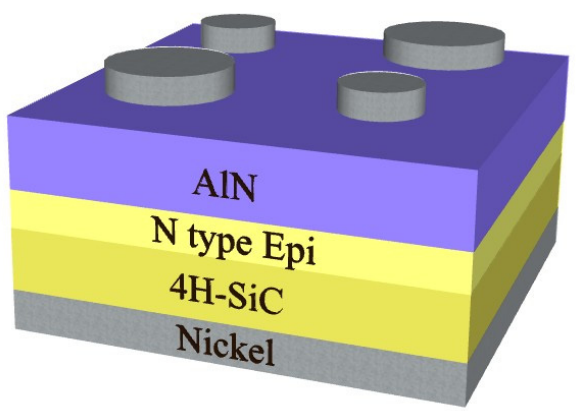

Figure 1. Structure of the fabricated AlN/4H-SiC Schottky barrier diode samples.

\section{Results and Discussion}

Figure 2a-c show scanning electron microscopy (SEM) images detailing the surface morphology of the manufactured AlN films. The AlN thin films in Figure $2 b, c$ display larger average grain size relative to the grain size of the film in Figure 2a.



(a)

(b)

(c)

Figure 2. AlN film morphology SEM imaging (a) as-grown, (b) $\mathrm{N}_{2}$-annealed, and (c) $\mathrm{O}_{2}$-annealed samples. 
Figure 3 shows the $\mathrm{O} 1 \mathrm{~s}$ and $\mathrm{Al} 2 \mathrm{p}$ XPS spectra of the AlN films obtained for the as-grown sample, as well as samples after annealing in either $\mathrm{N}_{2}$ or $\mathrm{O}_{2}$ gas. The $\mathrm{Al}-\mathrm{OH}$ and $\mathrm{O}-\mathrm{Al}$ peaks in the $\mathrm{O} 1 \mathrm{~s}$ spectrum of the as-grown sample are centered at 531.78 and $530.88 \mathrm{eV}$, respectively. After gas annealing, in the $\mathrm{N}_{2}$-annealed sample, $\mathrm{Al}-\mathrm{OH}$ and $\mathrm{O}-\mathrm{Al}$ binding energies shifted to $531.38 \mathrm{eV}$ and $530.56 \mathrm{eV}$, respectively. Said energies were $0.4 \mathrm{eV}$ and $0.32 \mathrm{eV}$ lower than those of the as-grown sample, respectively. Furthermore, in the $\mathrm{O}_{2}$ annealed sample, the Al-OH and O-Al binding energies shifted to $531.33 \mathrm{eV}$ and $530.52 \mathrm{eV}$, which in turn were lower compared with the binding energies of the $\mathrm{N}_{2}$-annealed sample. Additionally, the relative area of the $\mathrm{Al}-\mathrm{OH}$ peak decreased. The Al-N peak of the $\mathrm{Al}$ $2 \mathrm{p}$ spectrum was detected at $74.68 \mathrm{eV}$, and the corresponding $\mathrm{Al}-\mathrm{O}$ peak was centered at $73.78 \mathrm{eV}$. The ratios between these two components determined for the as-grown and $\mathrm{O}_{2}$-annealed samples were identical, while the relative area of the Al-N peak obtained for the $\mathrm{N}_{2}$-annealed sample increased to $47.4 \%$. The reason for the higher $\mathrm{O} 1 \mathrm{~s}$ binding energy in the as-grown sample than in the annealed samples was likely to be the result of chemisorption of oxygen or superficially adsorbed $\mathrm{OH}$ species [14]. The observed decrease in the relative $\mathrm{Al}-\mathrm{OH}$ peak area after annealing can be attributed to the cleavage of $\mathrm{O}-\mathrm{H}$ bonds at high temperatures [15]. Similarly, the decreased Al-O peak area in the Al $2 p$ spectrum of the $\mathrm{N}_{2}$-annealed sample indicated that $\mathrm{N}_{2}$ gas suppressed the formation of $\mathrm{Al}-\mathrm{O}$ bonds and increased the fraction of $\mathrm{Al}-\mathrm{N}$ bonds during annealing [14].
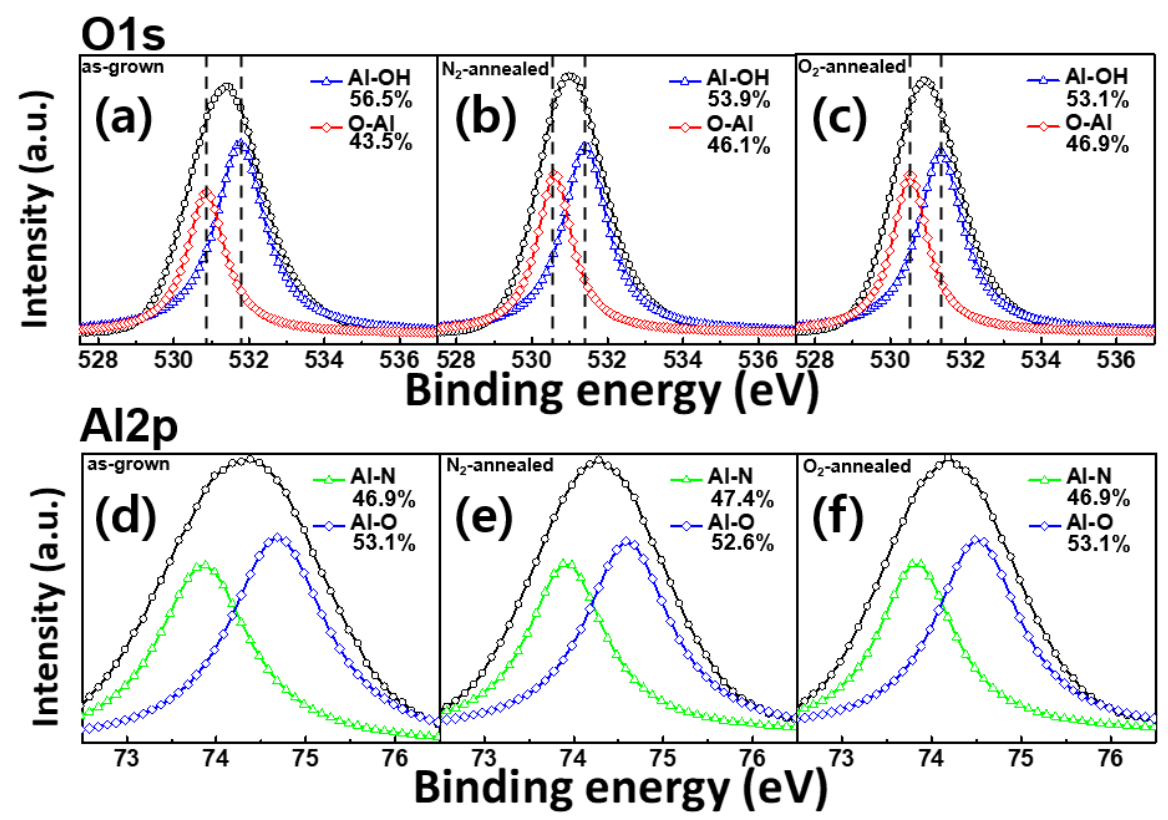

Figure 3. The results of XPS analysis of the fabricated AlN films performed before and after annealing; (a-c) the $\mathrm{O} 1 \mathrm{~s}$ peaks of the various AlN films where (a) relates to the as-grown sample, (b) the $\mathrm{N}_{2^{-}}$ annealed sample, and (c) the $\mathrm{O}_{2}$-annealed sample; (d-f) the $\mathrm{Al} 2 \mathrm{p}$ peaks with $\mathrm{Al}-\mathrm{N}$ and $\mathrm{Al}-\mathrm{O}$ sub-peaks of the different samples, with results in (d) for the as-grown sample (e), the $\mathrm{N}_{2}$-annealed sample, and (f) the $\mathrm{O}_{2}$-annealed sample.

The I-V characteristics of the annealed and non-annealed SBD devices obtained at room temperature are shown in Figure 4. The as-grown sample shows a current of $4.6 \times 10^{-5} \mathrm{~A}$ at a voltage of $5 \mathrm{~V}$. The corresponding current increased to $1.5 \times 10^{-4} \mathrm{~A}$ in the $\mathrm{N}_{2}$-annealed sample, while it decreased to $1.15 \times 10^{-6} \mathrm{~A}$ in the $\mathrm{O}_{2}$-annealed sample. The XPS analysis indicated that the $\mathrm{O} 1 \mathrm{~s}$ binding energy was higher in the as-grown sample than in the annealed samples. As previously mentioned, this is likely to have resulted from chemisorbed surface oxygen or superficially adsorbed $\mathrm{OH}$ species [15]. Consequently, the improved electrical characteristics of the $\mathrm{N}_{2}$ and $\mathrm{O}_{2}$-annealed samples were attributed to the decreased charge carrier trap concentration. Meanwhile, the Al-N peak area in the $\mathrm{Al}$ $2 p$ spectrum increased after $\mathrm{N}_{2}$ annealing because of the suppression of the $\mathrm{Al}-\mathrm{O}$ bond 
formation process. Thus, the purity of the $\mathrm{N}_{2}$-annealed sample appears to have increased as a result of the $\mathrm{N}_{2}$ gas exposure during annealing [16]. At the same time, it increased the electrical resistance of the AlN layer, thereby reducing its conductivity [17].

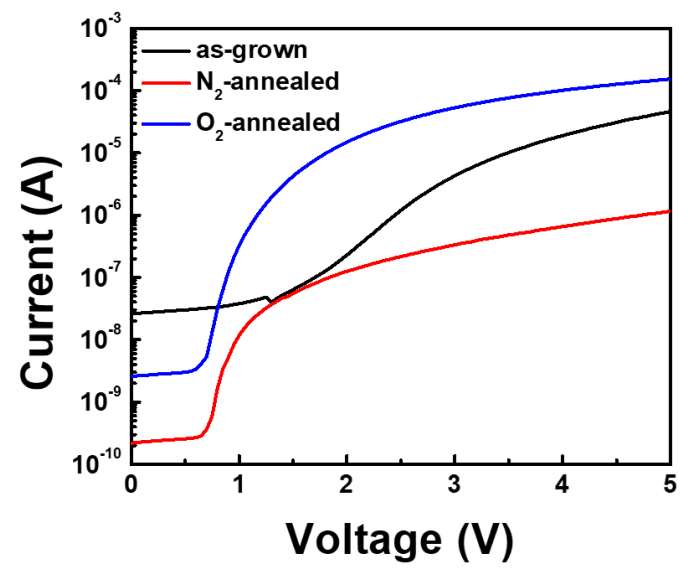

Figure 4. Current-voltage (I-V) characteristics of the AlN film Schottky barrier diode (SBD) devices obtained before and after annealing.

The I-V-T graphs obtained for the three studied samples in the temperature range from 475 to $300 \mathrm{~K}$ in steps of $25 \mathrm{~K}$ are shown in Figure 5. In these graphs, the turn-on voltage decreases with increasing temperature. Thermionic emission theory describes charge carrier activation at low currents and high temperatures [18]. Its governing equation shows the temperature dependence of the forward voltage:

$$
V=I R+\frac{k T \eta}{q} \ln \left(\frac{I}{A R^{* *} T^{2}}\right)
$$

where $\eta$ is the ideality factor, $q$ is the electronic charge, $k$ is Boltzmann's constant, $A$ is the contact area, $T$ is the temperature, and $R^{* *}$ is Richardson's constant. Obviously, the equation was shown to need low voltage in high temperature (Figure 5). The ideality factors for the as-grown, $\mathrm{N}_{2}$-annealed, and $\mathrm{O}_{2}$-annealed samples are 11.03, 2.79, and 4.65, respectively at $475 \mathrm{~K}$. The Richardson constant for $\mathrm{AlN}$ is $\approx 57.6 \mathrm{~A} \mathrm{~cm}^{-2} \mathrm{~K}^{-2}$ [4]. $R_{s}$ was calculated from the I-V-T curve. The obtained values were as follows; as-grown sample: $0.0044 \Omega ; \mathrm{N}_{2}$-annealed sample: $0.331 \Omega$; $\mathrm{O}_{2}$-annealed sample: $0.0187 \Omega$ for $1.75,1.85,0.9 \mathrm{~V}$ turn-on voltages at $300 \mathrm{~K}$, respectively. Thus, $R_{S}$ in the as-grown sample was lower than in the annealed sample at $300 \mathrm{~K}$. On the other hand, at $475 \mathrm{~K}$, the resistance of the as-grown sample was $0.015 \Omega$, while it was $0.2981 \Omega$ in the $\mathrm{N}_{2}$-annealed sample and $0.0005 \Omega$ in the $\mathrm{O}_{2}$-annealed sample. Consequently, the $\mathrm{O}_{2}$-annealed sample exhibited larger currents at elevated temperatures than the other samples. High-performance temperature sensors consume little power and exhibit good linearity and sensitivity [19]. The sensitivities of the fabricated SBD devices were measured at various forward currents.

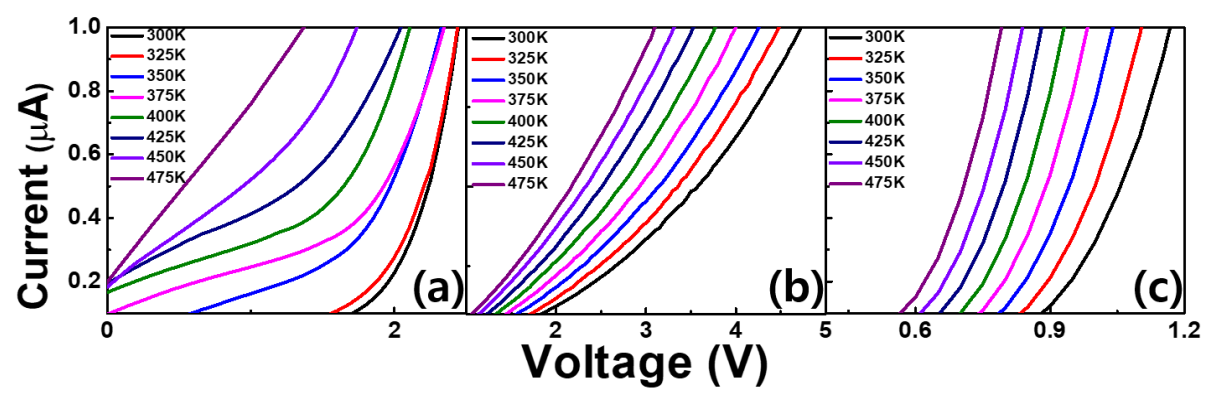

Figure 5. Forward current-voltage-temperature (I-V-T) characteristics of the fabricated AlN/4H-SiC SBD devices: (a) as-grown, (b) $\mathrm{N}_{2}$-annealed, (c) $\mathrm{O}_{2}$-annealed. 
Figure 6 shows the V-T graphs extracted from the respective I-V-T plots at temperatures between 475 and $300 \mathrm{~K}$ and currents between 0.5 and $1 \mathrm{~A}$. In all the V-T graphs, the temperature increases with decreasing voltage. For the as-grown sample, the peak current begins to decrease after achieving a maximum sensitivity of $9.77 \mathrm{mV} / \mathrm{K}$ at $0.5 \mu \mathrm{A}$. In contrast, the $\mathrm{N}_{2}$-annealed and $\mathrm{O}_{2}$-annealed samples exhibit relatively small sensitivities at low currents; however, their magnitudes increase to 9.37 and $2.16 \mathrm{mV} / \mathrm{K}$ at $1 \mu \mathrm{A}$, respectively. The sensitivity of the sample fabricated by Ao et al. was approximately $1.3 \mathrm{mV} / \mathrm{K}$ [20], which was 4.7 times lower than the value obtained for the as-grown sample in the present study. Furthermore, the $\mathrm{N}_{2}$-annealed and $\mathrm{O}_{2}$-annealed samples demonstrated the same trends as that observed in the temperature sensor fabricated by Tan et al. The latter possessed a sensitivity of approximately $1.59 \mathrm{mV} / \mathrm{K}$, which was 5.9 and 1.3 times lower than the maximum sensitivities of the $\mathrm{N}_{2}$-annealed and $\mathrm{O}_{2}$-annealed devices, respectively [21].
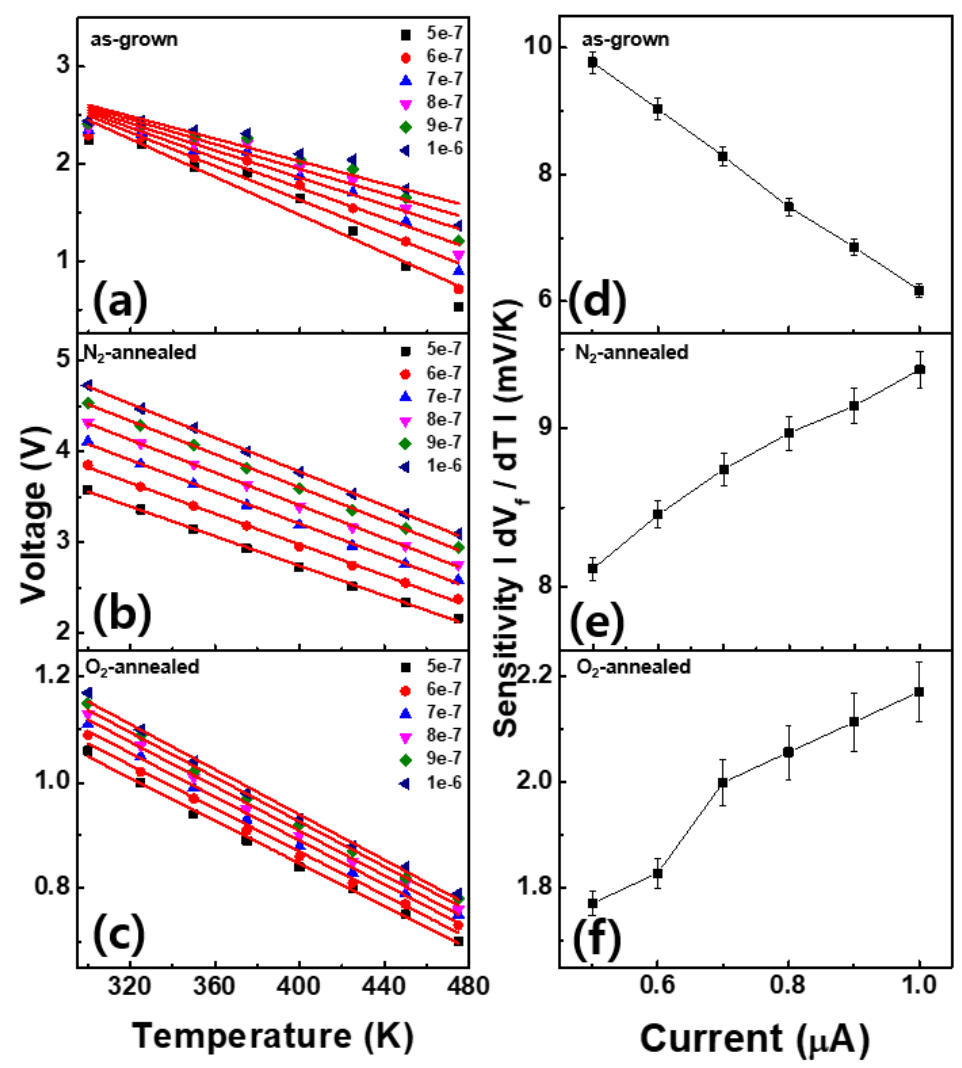

Figure 6. Forward voltage vs. temperature plots for the fabricated AlN/4H-SiC SBD devices at various currents: (a) as-grown, (b) $\mathrm{N}_{2}$-annealed, and (c) $\mathrm{O}_{2}$-annealed sample. sensitivity vs. current obtained from V-T plots, including error bars; (d) as-grown, (e) $\mathrm{N}_{2}$-annealed, and (f) $\mathrm{O}_{2}{ }^{-}$ annealed samples.

\section{Conclusions}

In this study, an AlN/SBD temperature sensor was fabricated by depositing an AlN thin film on an n-type $4 \mathrm{H}$-SiC substrate by RF sputtering. The effects of $\mathrm{N}_{2}$ and $\mathrm{O}_{2}$ annealing on the composition of the AlN layer and the thermal sensitivity and electrical characteristics of the produced device were examined. The high-temperature annealing process caused the cleavage of $\mathrm{Al}-\mathrm{OH}$ bonds. As a result, the relative area of the $\mathrm{Al}-\mathrm{O}$ peak increased, which was apparently because of a decrease in the number of oxygen vacancies. Additionally, $\mathrm{N}_{2}$ annealing increased the purity of the AlN film due to the lower number of Al-O bonds, essentially reducing the effective doping of the film. Consequently, the current decreased with the increasing electric resistance that resulted from the $\mathrm{N}_{2}$ annealing. Finally, the thermal sensitivity of the fabricated sensor was calculated from its 
V-T characteristics, which was extracted from the corresponding I-V-T plot. The sensitivity values obtained for the as-grown, $\mathrm{N}_{2}$-annealed, and $\mathrm{O}_{2}$-annealed samples exceeded the sensitivities of the sensors reported in the literature by $4.7,5.9$, and 1.3 times, respectively.

Author Contributions: Conceptualization, S.-W.J. and S.-M.K.; writing original draft, S.-W.J. and M.-C.S.; writing review and editing, S.-W.J., M.A.S. and S.-M.K.; methodology, S.-W.J.; project administration, S.-M.K.; validation, M.A.S., J.-M.O. and S.-M.K.; supervision, S.-M.K. All authors have read and agreed to the published version of the manuscript.

Funding: This work was supported by the KETEP Energy Education Program (20194010000050), and GRDC program through the National Research Foundation (NRF) grant funded by the MSIT of Korea (NRF-2018K1A4A3079552).

Institutional Review Board Statement: Not applicable.

Informed Consent Statement: Not applicable.

Data Availability Statement: Data is contained within the article.

Acknowledgments: The authors (Seung-Woo Jung, Myeong-Cheol Shin, and Sang-Mo Koo) thank Ichimura and department of Electrical and Mechanical Engineering, Nagoya Institute of Technology for allowing Research-Visit collaboration of graduate students.

Conflicts of Interest: The authors declare no conflict of interest.

\section{References}

1. Liang, J.; Nishida, S.; Hayashi, T.; Arai, M.; Shigekawa, N. Effects of interface state charges on the electrical properties of Si/SiC heterojunctions. Appl. Phys. Lett. 2014, 105, 151607. [CrossRef]

2. Cheng, H.; Sun, Y.; Zhang, J.X.; Zhang, Y.B.; Yuan, S.; Hing, P. AlN films deposited under various nitro-gen concentrations by RF reactive sputtering. J. Cryst. Growth 2003, 254, 46-54. [CrossRef]

3. Behera, L.; Pandey, N.; Gupta, M. Synthesis and characterization of AlN thin films deposited using DC and RF magnetron sputtering. In DAE Solid State Physics Symposium 2019, AIP Conference Proceedings; AIP Publishing LLC.: Melville, NY, USA, 2020; Volume 2265, p. 030310. [CrossRef]

4. Kim, D.H.; Min, S.J.; Oh, J.M.; Koo, S.M. Fabrication and Characterization of Oxygenated AlN/4H-SiC Heterojunction Diodes. Materials 2020, 13, 4335. [CrossRef] [PubMed]

5. Tanaka, S.; Shojiki, K.; Uesugi, K.; Hayashi, Y.; Miyake, H. Quantitative evaluation of strain relaxation in annealed sputterdeposited AlN film. J. Cryst. Growth 2019, 512, 16-19. [CrossRef]

6. Miyake, H.; Lin, C.-H.; Tokoro, K.; Hiramatsu, K. Preparation of high-quality AlN on sapphire by high-temperature face-to-face annealing. J. Cryst. Growth 2016, 456, 155-159. [CrossRef]

7. Benmoussa, A.; Soltani, A.; Schuhle, U.; Haenen, K.; Chong, Y.; Zhang, Y.-L.; Dahal, R.; Lin, J.Y.; Jiang, H.; Barkad, H.; et al. Recent developments of wide-bandgap semiconductor based UV sensors. Diam. Relat. Mater. 2009, 18, 860-864. [CrossRef]

8. Liu, G.; Yan, C.; Zhou, G.; Qin, Z.; Zhou, Q.; Zheng, R.; Sun, Z. Defects induced broad spectral photore-sponse of PVT-grown bulk AlN crystals. Scr. Mater. 2018, 154, 45-48. [CrossRef]

9. Rahman, H.; Thakur, J.S.; Rimai, L.; Perooly, S.; Naik, R.R.; Zhang, L.; Auner, G.W.; Newaz, G. Dual-mode operation of a $\mathrm{Pd} / \mathrm{AlN} / \mathrm{SiC}$ device for hydrogen sensing. Sensor. Actuator. B Chem. 2008, 129, 35-39. [CrossRef]

10. Min, S.J.; Shin, M.C.; Thi Nguyen, N.; Oh, J.M.; Koo, S.M. High-performance temperature sensors based on dual $4 \mathrm{H}-\mathrm{SiC}$ JBS and SBD devices. Materials 2020, 13, 445. [CrossRef]

11. Le, X.; Wang, X.; Pang, J.; Liu, Y.; Fang, B.; Xu, Z.; Gao, C.; Xu, Y.; Xie, J. A high performance humidity sensor based on surface acoustic wave and graphene oxide on AlN/Si layered structure. Sensor. Actuator. B Chem. 2018, 255, 2454-2461. [CrossRef]

12. Jung, J.C.; Koo, S.M. The Effect of Catalytic Metal Work Functions and Interface States on the High Tem-Perature SiC-Based Gas Sensors. J. Korean Inst. Electr. Electron. Mater. Eng. 2011, 24, 280-284.

13. Li, D.; Song, X.; Xu, J.; Wang, Z.; Zhang, R.; Zhou, P.; Zhang, H.; Huang, R.; Wang, S.; Zheng, Y.; et al. Optical properties of thickness-controlled $\mathrm{MoS}_{2}$ thin films studied by spectroscopic ellipsometry. Appl. Surf. Sci. 2017, 421, 884-890. [CrossRef]

14. Rao, T.P.; Kumar, M.S. Resistivity Stability of Ga Doped ZnO Thin Films with Heat Treatment in Air and Oxygen Atmospheres. J. Cryst. Process. Technol. 2012, 2, 72-79. [CrossRef]

15. Xiang, Y.; Zhou, C.; Jia, E.; Wang, W. Oxidation precursor dependence of atomic layer deposited $\mathrm{Al}_{2} \mathrm{O}_{3}$ films in a-Si: $\mathrm{H}_{(\mathrm{i})} / \mathrm{Al}_{2} \mathrm{O}_{3}$ surface passivation stacks. Nano. Res. Letter. 2015, 10, 1-8. [CrossRef] [PubMed]

16. Cao, D.; Cheng, X.; Xie, Y.-H.; Zheng, L.; Wang, Z.; Yu, X.; Wang, J.; Shen, D.; Yu, Y. Effects of rapid thermal annealing on the properties of AlN films deposited by PEALD on AlGaN/GaN heterostructures. RSC Adv. 2015, 5, 37881-37886. [CrossRef]

17. Kale, A.; Brusa, R.; Miotello, A. Structural and electrical properties of AlN films deposited using reactive RF magnetron sputtering for solar concentrator application. Appl. Surf. Sci. 2012, 258, 3450-3454. [CrossRef] 
18. Kumar, V.; Maan, A.S.; Akhtar, J. Barrier height inhomogeneities induced anomaly in thermal sensitivity of Ni/4H-SiC Schottky diode temperature sensor. J. Vac. Sci. Technol. B 2014, 32, 041203. [CrossRef]

19. Bakker, A.; Huijsing, J. Micropower CMOS temperature sensor with digital output. IEEE J. Solid State Circuits 1996, 31, 933-937. [CrossRef]

20. Li, L.; Li, X.; Pu, T.; Cheng, S.; Li, H.; Ao, J.P. Vertical Gan-based Temperature Sensor by Using TiN Anode Schottky Barrier Diode. IEEE Sensor. J. 2020, 21, 1273-1278. [CrossRef]

21. Guo, Q.; Lu, F.; Tan, Q.; Zhou, T.; Xiong, J.; Zhang, W. $\mathrm{Al}_{2} \mathrm{O}_{3}$-Based a-IGZO Schottky Diodes for Tempera-ture Sensing. Sensors 2019, 19, 224. [CrossRef] [PubMed] 